Research Article

\title{
Keratorefractive Surgery Outcomes in Keratoconus Suspect Patients
}

\author{
Milad Abdolahian, ${ }^{1,2}$ Mohammad Ali Moalem, ${ }^{2}$ Mohammadreza Jahady Hoseiny, ${ }^{2}$ \\ Farsad Noorizadeh $\left(\mathbb{D},{ }^{1}\right.$ and Athar Zareei ${ }^{2}$ \\ ${ }^{1}$ Basir Eye Health Research Center, Tehran 14186 43113, Iran \\ ${ }^{2}$ Poostchi Ophthalmology Research Center, Shiraz 7134997446, Iran \\ Correspondence should be addressed to Farsad Noorizadeh; noorizadeh.farsad@yahoo.com
}

Received 17 August 2020; Revised 7 November 2020; Accepted 18 November 2020; Published 2 December 2020

Academic Editor: Alessandro Meduri

Copyright (c) 2020 Milad Abdolahian et al. This is an open access article distributed under the Creative Commons Attribution License, which permits unrestricted use, distribution, and reproduction in any medium, provided the original work is properly cited.

\begin{abstract}
Purpose. To examine the outcomes of keratorefractive surgeries in keratoconus suspect patients. Methods. This study included 192 keratoconus suspects (351 eyes), treated with photorefractive keratectomy (PRK) (211 eyes), Lasik (96 eyes), and FemtoLasik (44 eyes) surgeries in an eye clinic. The best spectacle-corrected visual acuity (BSCVA) and subjective refraction were evaluated preoperatively and postoperatively (three months and five years after the procedure). The Orbscan II topography system was also used preoperatively and five years after the procedure. Results. The patients' mean age was $31.6 \pm 5.49$ years (range: 21-47 years) in the last follow-up. There was no significant difference between the preoperative and postoperative mean values of BSCVA in any of the surgical methods $(P=0.49)$. The mean spherical equivalent, cylindrical power, corneal curvature, the thinnest corneal thickness, and the central corneal thickness decreased significantly in the last follow-up $(P<0.001)$. Four patients $(3.50 \%)$ in the PRK group and one patient $(1.85 \%)$ in the Lasik group needed glasses in the last follow-up. Eleven cases of corneal ectasia were detected in the last follow-up (six eyes of four patients [2.84\%] and five eyes of four patients [5.20\%] in the PRK and Lasik groups, respectively). Conclusion. In the present study, the high risk of postoperative ectasia was detected in keratoconus suspects following PRK and Lasik surgeries. According to the results, it can be concluded that Femto-Lasik surgery provides better outcomes than Lasik and PRK. Overall, the surgical criteria are suggested to be evaluated case by case, and the patients must be followed up over time to assess the corneal topography and refraction stability.
\end{abstract}

\section{Introduction}

Keratoconus is a progressive noninflammatory disorder of the cornea, characterized by stromal thinning, along with localized conical protrusion. This disease can be categorized into keratoconus suspect (KCS), mild keratoconus, moderate keratoconus, and severe keratoconus, depending on its severity. Moderate and severe categories of keratoconus can be detected easily, using retinoscopic, biomicroscopic, and pachymetry evaluations, combined with corneal topography $[1,2]$. However, diagnosis of the early stages of keratoconus, known as KCS, is challenging.

Patients with KCS show complete contraindication to refractive surgery [3]. The precise identification of KCS is the primary concern of refractive surgeons, as KCS seems to be the primary cause of corneal ectasia following refractive procedures $[4,5]$. Therefore, any level of keratoconus should be detected before refractive surgery to avoid corneal ectasia. Several studies have shown that refractive findings of individuals with normal corneal topography are similar to those of patients with KCS. In this regard, Chelala et al. and Guedj et al. reported excellent photorefractive keratectomy (PRK) results in long-term followups of patients with grade I/II keratoconus and KCS, respectively $[6,7]$. On the other hand, other researchers suggest that further assessment is required before determining whether KCS should be considered in refractive surgeries $[8,9]$. Corneal ectasia may occur following Lasik 
and PRK surgeries, although some studies have shown its higher frequency after Lasik surgery $[10,11]$. During the Keratorefractive surgeries, the epithelium with underlying Bowman's layer and part of the anterior stroma were removed. It is important that the superficial epithelial layer is recovered and leads to corneal transparency. Healing of the corneal epithelium mostly depends on the basement membrane remodeling of limbal stem cells [12]. There are receptors of cytokines and growth factors for epithelial cells and keratocytes. Thus, in these cells, the inflammatory mediators probably are important for the recovery of corneal tissue during wounding. Keratocytes secrete cytokines to modulate the proliferation, migration, and differentiation of epithelial and stromal cells into fibroblasts and myofibroblasts $[3,9]$ and to repair the stroma [6] when there are epithelial damage and loss of the basement membrane function and also stromal cell. During stromal healing, the transforming growth factor- $\beta$ (TGF- $\beta$ ) system activates and leads to keratocytes transformation that results in contractile and motile myofibroblasts [12]. Several studies have confirmed the role of epithelial cells in the release of growth factors, in addition to cytokines that are necessary for regeneration process of cornea after PRK [13]. In a study, the combination role of cytochrome $c$ peroxidase (CCP) and basic fibroblast growth factor (bFGF) on the healing rate of the corneal epithelium after Phototherapeutic keratectomy in transgenic mice was studied, and it was suggested that CCP/bFGF combination eyedrops could be beneficial for reepithelialization after refractive surgery [14].

Statistically significant data found in a study about thickness reduction after epithelium removal during corneal collagen crosslinking in keratoconus patients [15]. Corneal dehydration was reported with dextran solutions that leads to corneal thining, whereas the corneal thinning could be avoided by alternative riboflavin diffusion medium, such as the hydroxylpropyl-methyl-cellulose (HPMC) during the soaking and irradiation time instead of dextran that it caused the risk of endothelial damage and postoperative haze is decreased [15].

Today, femtosecond laser technology has provided more uniform, thinner, and reproducible corneal flaps [16]. Previous studies have described preoperative risk factors for corneal ectasia following refractive surgery, including low corneal thickness before surgery, low residual stromal bed (RSB) thickness, high myopia, abnormal corneal topography, and younger age [17]. Although several risk factors have already been described, and technologies and screening methods are being improved, post-Lasik and post-PRK corneal ectasia still occur $[3,18]$.

Since only $50 \%$ of corneal ectasia cases following Lasik surgery occur within the first year [19], this disorder needs to be investigated in long-term follow-ups. The current study aimed to assess and compare the visual and refractive results and the incidence of corneal ectasia following different types of refractive surgery in patients with KCS in a long-term follow-up. Also, we assessed the risk factors in patients with corneal ectasia to find the most important prognostic risk factors for ectasia.

\section{Materials and Methods}

A total of 192 individuals with KCS (351 eyes) were enrolled in this retrospective study. Screening tests, including manifest refraction, best-corrected visual acuity (BSCVA), corneal topography (Orbscan IIz; Bausch and Lomb, Rochester, NY, USA), indirect ophthalmoscopy, and slitlamp examination, were performed for all patients. The BSCVA and subjective refraction were measured preoperatively and postoperatively (three months and five years after the procedure). The Orbscan corneal topography system was also used preoperatively and postoperatively (five years after the procedure). KCS was defined as no clinical sign of keratoconus, minor topographic asymmetry, steep corneal curvature more than $47.0 \mathrm{D}$, central corneal thickness (CCT) less than $500 \mu \mathrm{m}$, and oblique astigmatism more than $1.5 \mathrm{D}$ [20].

The inclusion criteria for refractive surgery were as follows: (1) a stable refractive error for at least six months prior to the procedure; (2) avoidance of contact lenses for four weeks before the procedure. On the other hand, the exclusion criteria for surgery were as follows: (1) obvious ectasia or scarring on the slit-lamp exam; (2) BSCVA less than 20/40; (3) manifest keratoconus in the opposite eye; (4) evidence of apical thinning of the cornea; (5) RSB thickness less than $300 \mathrm{~mm}$; (6) history of ocular surgery; (7) family history of keratoconus; (8) history of ocular trauma, glaucoma, or corneal disorders; (9) pregnancy.

This study was approved by the Ethics Committee of Shiraz University of Medical Sciences, Shiraz, Iran. Each participant signed an informed consent form after receiving explanations about the goals of the study. All procedures in this study were based on the principles of the Declaration of Helsinki.

2.1. Surgeries. Two surgeons performed the surgeries (PRK, Lasik, or Femto-Lasik). In the PRK group, epithelial debridement was carried out with a blunt hockey scalpel over a circular area (6-8 $\mathrm{mm}$ diameter) after applying 30\% ethanol for 15 minutes. In the Lasik group, a narrow circular flap was created on the eye surface with a Hansatome microkeratome. After folding back the hinged flap, the surgeon could access the stroma and alter the shape of the corneal tissue with an excimer laser. Next, the QUEST EC5000 excimer laser (NIDEK, Japan), working at a repetition rate of $40 \mathrm{~Hz}$, was used, based on the slit-scan technique for laser treatment. The eye tracker was set at a speed of $1 \mathrm{MHz}$ with a 6-ms latency. In all subjects, ablation was centered on the entrance pupil center, and the treated optical zone, enclosed by a $2 \mathrm{~mm}$ transition zone, had a diameter of $5-6 \mathrm{~mm}$, depending on the thickness of the cornea and pupil size.

After applying laser therapy, a bandage contact lens and preservative-free levofloxacin 5\% eye drop were prescribed (Oftaquix $5 \mathrm{mg} / \mathrm{mL}$ eye drops; Santen UK Limited, Salisbury Hall, St Albans, AL2 1BU, UK). After epithelium healing (about 3-5 days), the bandage lenses were immediately discarded. Surgery was also performed for the other eye at the same time if needed. Postoperative medications, 
including preservative-free artificial tear drops and fluorometholone 0.1\% (Allergan, Lachen, Switzerland), were used every two hours during daytime and twice a day for one month, respectively; they were then narrowed over the following 60 days.

In the Femto-Lasik group, a $110 \mathrm{~mm}$ superior hinged flap was made, using a Femto laser (Ziemer Ophthalmic Systems AG, Port, Switzerland), the surgeon lifted the flap, and ablation was performed with a WaveLight Allegretto EX500 excimer laser (Alcon, TX, USA) after topical anesthesia with proparacaine hydrochloride $0.5 \%$. An optical zone of $6.5 \mathrm{~mm}$ with a blend zone of $1.25 \mathrm{~mm}$ was then selected. Postoperatively, chloramphenicol $0.5 \%$ (every six hours for one week) and betamethasone $0.1 \%$ (every six hours for one week) were prescribed.

2.2. Statistical Analyses. Data were evaluated using the SPSS.21 software (SPSS Inc, Chicago, Illinois, USA). The normality of the data was investigated using the Kolmogorov-Smirnov test, which showed a normal distribution for quantitative data. The mean and standard deviation of refraction results and topographic results before the operation, three months, and five years after operation was calculated and reported for each kind of refractive surgery separately. Depending on the data distribution, paired $t$-tests or Wilcoxon's paired test was utilized to check the significant differences between preoperative and two postoperative follow-up sessions in 3 months and 5 years after refractive surgeries. In all analyses, a $P$-value of less than 0.05 was regarded to be significant.

\section{Results and Discussion}

The results of refraction, visual acuity, and topographic results were separately reported in each kind of refractive surgery, and the challenging cases in each kind of refractive surgery were also discussed case by case.

3.1. PRK. A total of 114 individuals (211 eyes) with KCS were considered suitable for treatment with PRK.

3.2. Refraction and Vision Acuity Results. The preoperative and postoperative data of patients are presented in Table 1. No significant changes were detected in BSCVA in the threemonth and five-year follow-ups, compared to the preoperative BSCVA values ( $P=0.523$ and $P=0.751$, respectively). Figure 1 presents the BCVA gain and loss of lines five years after surgery. In the last follow-up, the eye lost one line of BSCVA in one eye $(0.4 \%)$, two lines in five eyes $(2.3 \%)$, and three lines in two eyes (0.9\%). Two eyes showed a one-line gain, one eye showed a two-line gain, and two eyes showed a three-line gain, while the other eyes maintained their preoperative status.

The mean spherical equivalent (SE) refraction significantly reduced by $3.55 \pm 2.01 \mathrm{D}$ in the three-month follow-up $(P<0.001)$ and by $3.55 \pm 1.92 \mathrm{D}$ in the five-year follow-up $(P<0.001)$. The SE did not show any significant changes from the three-month follow-up to the last follow-up $(P=0.674)$.
Also, the cylindrical component of refractive error reduced significantly from $-0.97 \pm 0.99 \mathrm{D}$ preoperatively to $-0.44 \pm 0.50 \mathrm{D}$ in the three-month follow-up $(P<0.001)$ and $-0.30 \pm 0.42 \mathrm{D}$ in the last follow-up $(P<0.001)$. Also, astigmatism decreased significantly from the three-month followup to the last follow-up $(P<0.001)$. The subgroups, based on the orientation of the preoperative refractive cylinder axis, were as follows: against-the-rule $\left(60-120^{\circ}\right)$, including 29 eyes (13.74\%); with-the-rule $\left(0-30\right.$ or $\left.150-180^{\circ}\right)$, including 110 eyes (52.13\%); and oblique (30-60 or $\left.120-150^{\circ}\right)$, including 32 eyes (15.16\%). Three patients needed glasses due to significant myopic or astigmatic regression in the final follow-up.

3.3. Topographic Results. The results indicated significant reductions in the mean CCT and the thinnest point of the cornea from $502.81 \pm 33.76 \mu \mathrm{m}$ and $490.84 \pm 34.46 \mu \mathrm{m}$ preoperatively to $431.75 \pm 46.51 \mu \mathrm{m} \quad(P<0.001) \quad$ and $413.36 \pm 49.08 \mu \mathrm{m}(P<0.001)$ in the last follow-up. The mean values of maximum and minimum curvatures reduced significantly from $45.00 \pm 1.78 \mathrm{D}$ and $43.66 \pm 1.58 \mathrm{D}$ preoperatively to $41.50 \pm 1.78 \mathrm{D}(P<0.001)$ and $40.55 \pm 1.78 \mathrm{D}$ $(P<0.001)$ in the last follow-up, respectively. According to the analysis of corneal curvature shape with the Orbscan topography, 98 eyes $(46.4 \%)$ showed a symmetric bow-tie pattern, four eyes (1.8\%) showed a skewed radial axis, 99 eyes (46.9\%) showed inferior steepening, and ten eyes (4.7\%) showed superior steepening. Figure 2 presents the subgroups of preoperative corneal topographic shapes. Six eyes (2.84\%) of four patients developed corneal ectasia after PRK. The preoperative and postoperative data of patients with ectasia are presented in Table 2.

Case 1: A 35-year-old female underwent PRK of both eyes with preoperative refractions of $-8.50-4.00 \times 180$ in the right eye and $-10.25-4.00 \times 171$ in the left eye. The preoperative corneal topographic pattern was symmetric bow-tie (K-max: $48.3 \mathrm{D}$ and K-min: $44.8 \mathrm{D}$ in the right eye; and K-max: $47.9 \mathrm{D}$ and K-min: $44.4 \mathrm{D}$ in the left eye). The preoperative CCT was $515 \mu \mathrm{m}$ OD and $516 \mu \mathrm{m}$ OS. Bilateral corneal ectasia was detected in the eye with a corneal topography pattern of inferior steepening in the last follow-up (K-max: $42.4 \mathrm{D}$ and K-min: 38.7 D in the right eye; and K-max: $40.6 \mathrm{D}$ and K-min: $38.0 \mathrm{D}$ in the left eye). The CCT was $379 \mu \mathrm{m}$ in the right eye and $356 \mu \mathrm{m}$ in the left eye in the last follow-up. The preoperative BSCVA was 0.9 in both eyes, which changed to 0.6 in the last follow-up.

Case 2: A 37-year-old male underwent PRK of both eyes with preoperative refractions of $-3.00-1.75 \times 153$ in the right eye and $-4.00-2.25 \times 10$ in the left eye. Both eyes showed a BSCVA of $10 / 10$ preoperatively. The preoperative corneal topographic pattern was symmetric bowtie (K-max: $43.5 \mathrm{D}$ and K-min: $42.0 \mathrm{D}$ in the right eye; and K-max: $43.0 \mathrm{D}$ and K-min: $41.3 \mathrm{D}$ in the left eye). The preoperative CCT was $491 \mu \mathrm{m}$ OD and $492 \mu \mathrm{m}$ OS. The left eye developed corneal ectasia (K-max: $38.4 \mathrm{D}$ and $\mathrm{K}$-min, $37.9 \mathrm{D}$ ) in the last follow-up. The postoperative CCT at five years was $426 \mu \mathrm{m}$ in the right eye and 
TABLE 1: The preoperative and postoperative data of patients.

\begin{tabular}{|c|c|c|c|}
\hline Parameters & Preoperative & Three-month follow-up & Five-year follow-up \\
\hline \multicolumn{4}{|c|}{ PRK $(n=211)$} \\
\hline BSCVA & $0.99 \pm 0.04$ & $0.99 \pm 0.36$ & $0.99 \pm 0.45$ \\
\hline$P$ value & & $P=0.523$ & $P=0.751$ \\
\hline SUB SE & $-3.67 \pm 2.01$ & $-0.11 \pm 0.317$ & $-0.12 \pm 0.25$ \\
\hline$P$ value & & $P<0.001$ & $P<0.001$ \\
\hline SUB AST & $-0.97 \pm 0.99$ & $-0.44 \pm 0.50$ & $-0.30 \pm 0.42$ \\
\hline$P$ value & & $P<0.001$ & $P<0.001$ \\
\hline \multicolumn{4}{|c|}{ Lasik $(n=96)$} \\
\hline BSCVA & $0.99 \pm 0.03$ & $0.98 \pm 0.04$ & $0.97 \pm 0.07$ \\
\hline$P$ value & & $P=0.537$ & $P=0.203$ \\
\hline SUB SE & $-3.99 \pm 2.41$ & $-0.10 \pm 0.36$ & $-0.08 \pm 0.31$ \\
\hline$P$ value & & $P<0.001$ & $P<0.001$ \\
\hline SUB AST & $-1.58 \pm 1.50$ & $-0.51 \pm 0.50$ & $-0.39 \pm 0.46$ \\
\hline$P$ value & & $P<0.001$ & $P<0.001$ \\
\hline \multicolumn{4}{|c|}{ Femto-Lasik $(n=44)$} \\
\hline BSCVA & $0.98 \pm 0.06$ & $0.99 \pm 0.02$ & $1.00 \pm 0.00$ \\
\hline$P$ value & & $P=0.180$ & $P=0.109$ \\
\hline SUB SE & $-3.28 \pm 2.57$ & $-0.15 \pm 0.26$ & $-0.07 \pm 0.23$ \\
\hline$P$ value & & $P<0.001$ & $P<0.001$ \\
\hline SUB AST & $1.26 \pm 1.41$ & $-0.29 \pm 0.38$ & $-0.27 \pm 0.34$ \\
\hline$P$ value & & $P<0.001$ & $P<0.001$ \\
\hline
\end{tabular}

BSCVA = best spectacle-corrected visual acuity; SUB SE = subjective spherical equivalent; SUB AST = subjective astigmatism.

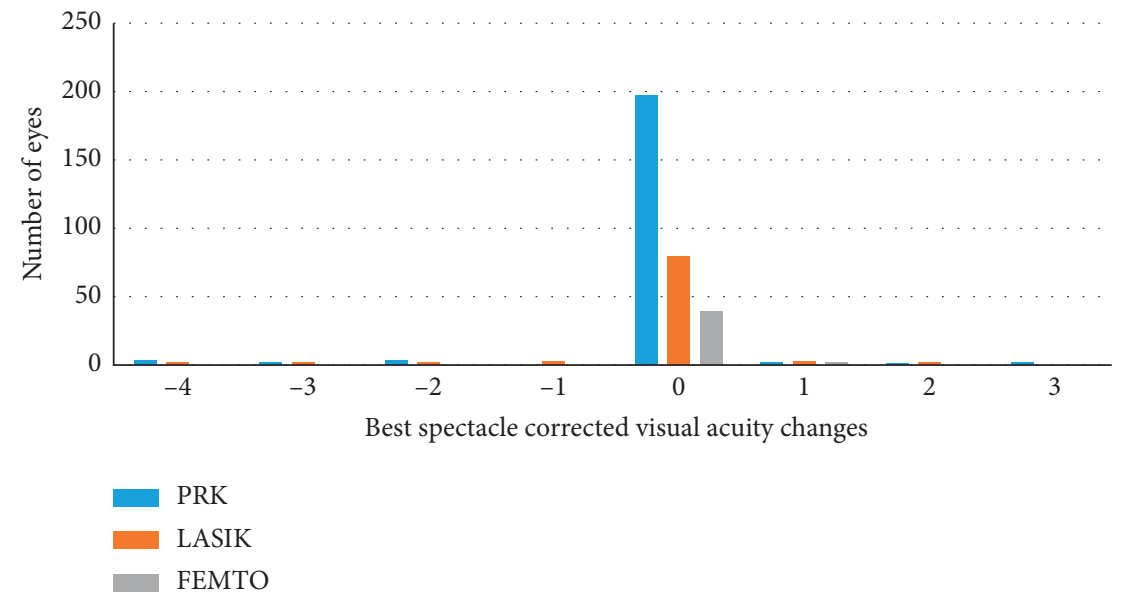

FIGURE 1: Postoperative losses and gains of the best spectacle corrected visual acuity (BSCVA) lines.

$408 \mu \mathrm{m}$ in the left eye. The right eye had no refractive error with UCVA of 10/10, while the left eye showed a refractive error of -0.50 with BSCVA of $6 / 10$ in the last follow-up.

Case 3: A 33-year-old female underwent PRK in both eyes with preoperative refractions of $-2.00-0.50 \times 180$ in the right eye and $-1.75-0.50 \times 168$ in the left eye. Both eyes showed a BSCVA of 10/10 preoperatively. The preoperative corneal topographic pattern was inferior steepening (K-max: 43.6 D and K-min: 42.5 D in the right eye; and K-max: 43.9 D and K-min: 42.7 D in the left eye). The preoperative CCT was $529 \mu \mathrm{m}$ OD and $524 \mu \mathrm{m}$ OS. Corneal ectasia developed in the left eye (K-max: $38.4 \mathrm{D}$ and K-min: $37.9 \mathrm{D}$ ) in the last follow-up. The postoperative CCT at five years was $483 \mu \mathrm{m}$ in the right eye and
$456 \mu \mathrm{m}$ in the left eye. The right eye had no refractive error with UCVA of 10/10, while the left eye showed a refractive error of $-0.50-160$ with BSCVA of $6 / 10$ in the last followup.

Case 4: A 37-year-old female underwent bilateral PRK with preoperative refractions of $-6.50-1.75 \times 10$ in the right eye and $-6.00-1.75 \times 160$ in the left eye. Each eye had a BSCVA value of 10/10 preoperatively. The preoperative corneal topographic pattern was superior steepening and symmetric bow-tie in the right and left eyes, respectively (K-max: $46.7 \mathrm{D}$ and K-min: $44.9 \mathrm{D}$ in the right eye; and K-max: 47.2 D and K-min: 45.7 D in the left eye). The preoperative CCT was $482 \mu \mathrm{m}$ OD and $480 \mu \mathrm{m}$ OS. Corneal ectasia developed in the right eye with a significant inferior steepening pattern, and the 


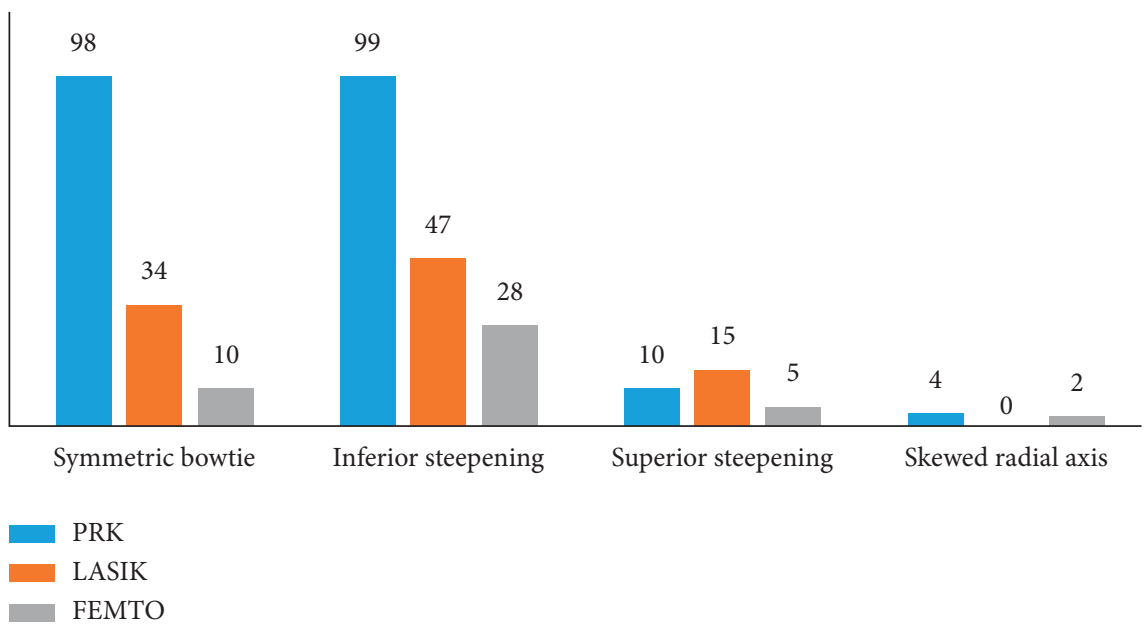

FIgURE 2: Subgroups of preoperative corneal topographic shapes.

left eye with an irregular corneal topographic pattern (K-max: 40.2 D and K-min: 39.1 D in the right eye; and K-max: $42.1 \mathrm{D}$ and K-min: $40.8 \mathrm{D}$ in the left eye) in the last follow-up. The postoperative CCT at five years was $367 \mu \mathrm{m}$ in the right eye and $373 \mu \mathrm{m}$ in the left eye. The right eye showed refractions of $-0.25-0.50 \times 100$ with a BSCVA of $8 / 10$ and the left eye showed refractions of $-1.00 \times 115$ with BSCVA of 7/10 in the last follow-up.

3.4. Lasik Surgery. In this study, 54 cases of KCS (96 eyes) were considered eligible for Lasik surgery.

3.5. Refraction and Vision Acuity Results. The preoperative and postoperative data of patients are presented in Table 1. No significant changes were identified in the BSCVA values in the three-month and five-year follow-ups, compared to the preoperative values $(P=0.537$ and $P=0.203$, respectively). Figure 1 shows the gains and losses of BSCVA lines five years after the procedure. In the last follow-up, one line of BSCVA decreased in four eyes (4.16\%), two lines in one eye (1.04\%), three lines in two eyes (2.08\%), and four lines in two eyes $(2.08 \%)$. Four eyes showed a one-line gain, two eyes showed a two-line gain, and the other eyes maintained their preoperative BSCVA value. In the five-year and three-month follow-ups, the mean SE reduced significantly by $3.90 \pm 2.34 \mathrm{D}(P<0.001)$ and $3.89 \pm 2.40 \mathrm{D}(P<0.001)$, respectively. According to the paired comparisons, SE showed no significant difference in the threemonth and five-year follow-ups $(P=0.654)$. Our results showed a significant decrease in mean astigmatism by $1.06 \pm 1.32 \mathrm{D}$ in the three-month follow-up $(P<0.001)$ and $1.18 \pm 1.28 \mathrm{D}$ in the final follow-up $(P<0.001)$. According to the paired comparisons, astigmatism reduced significantly from the three-month follow-up to the last follow-up $(P<0.001)$. The subgroups, based on the orientation of the preoperative refractive cylinder axis, were as follows: againstthe-rule, including nine eyes $(9.37 \%)$; with-the-rule, including 65 eyes (67.70\%); and oblique, including 14 eyes (14.58\%).
3.6. Topographic Results. The results revealed that the mean of the thinnest point of the cornea and CCT reduced significantly from $532.05 \pm 32.08 \mu \mathrm{m}$ and $544.67 \pm 32.78 \mu \mathrm{m}$ preoperatively to $444.81 \pm 62.84 \mu \mathrm{m} \quad(P<0.001)$ and $465.27 \pm 59.12 \mu \mathrm{m}$ $(P<0.001)$ in the last follow-up, respectively. The mean values of maximum and minimum curvatures reduced significantly from $45.62 \pm 1.73 \mathrm{D}$ and $43.74 \pm 1.66 \mathrm{D}$ preoperatively to $41.47 \pm 2.07 \mathrm{D}(P<0.001)$ and $40.38 \pm 1.93 \mathrm{D}(P<0.001)$ in the last follow-up, respectively. According to the curvature shape analysis by the Orbscan topography system, it was found that 34 eyes (35.4\%) had a symmetric bow-tie pattern, 47 eyes (48.9\%) had an inferior steepening pattern, and 15 eyes (15.6\%) had a superior steepening pattern. Figure 2 presents the subgroups of preoperative corneal topographic shapes. The corneal ectasia was detected in five eyes (5.2\%) of four patients after Lasik surgery. The preoperative and postoperative data of patients with ectasia are presented in Table 2.

CASE 1: A 34-year-old female underwent Lasik surgery in both eyes with a preoperative refractive error of $+4.50-3.00 \times 27$ in the right eye and $+3.25-1.75 \times 133$ in the left eye. Both eyes had a BSCVA value of $10 / 10$ preoperatively. The preoperative corneal topographic pattern was superior steepening and symmetric bow-tie in the right eye and the left eye, respectively (K-max: $45.0 \mathrm{D}$ and K-min: 41.9 D in the right eye; and K-max: $43.8 \mathrm{D}$ and K-min: $41.7 \mathrm{D}$ in the left eye). The CCT was $560 \mu \mathrm{m}$ OD and $559 \mu \mathrm{m}$ OS preoperatively. Corneal ectasia was found in the right eye (K-max: $46.1 \mathrm{D}$ and $\mathrm{K}$-min: $43.3 \mathrm{D}$ ). The postoperative CCT was $517 \mu \mathrm{m}$ in the right eye and $524 \mu \mathrm{m}$ in the left eye in the last follow-up. The right eye showed a BSCVA value of 5/10 with a refractive error of $+2.00-2.00 \times 5$, and the left eye showed a BSCVA value of 10/10 with a refractive error of $+1.75-1.00 \times 150$ in the last follow-up.

CASE 2: A 32-year-old female underwent Lasik surgery in both eyes with a preoperative refractive error of $+3.25-6.50 \times 180$ in the right eye and $+4.50-7.00 \times 5$ in 


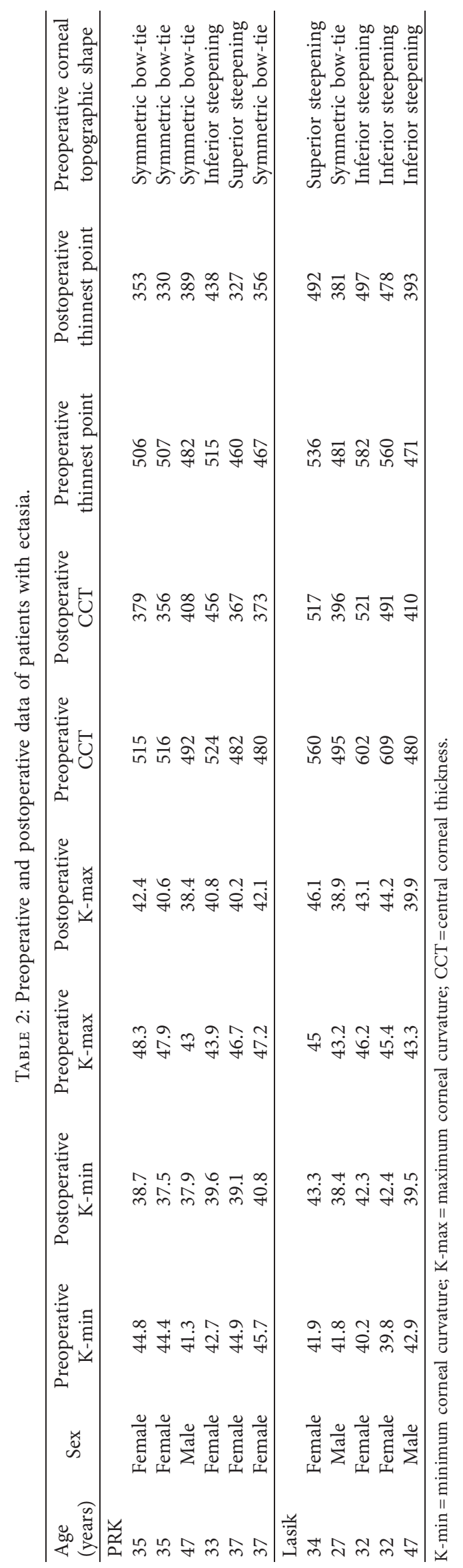


the left eye. Preoperatively, BSCVA was 10/10 in both eyes. The preoperative corneal topographic pattern was inferior steepening in both eyes (K-max: 46.2 D and K-min: $40.2 \mathrm{D}$ in the right eye; and K-max: $43.1 \mathrm{D}$ and K-min: $42.3 \mathrm{D}$ in the left eye). The preoperative CCT was $602 \mu \mathrm{m}$ OD and $609 \mu \mathrm{m}$ OS. Both eyes showed a BSCVA value of $8 / 10$ with a refractive error of $-0.50-60$ in the right eye and -1.00-70 in the left eye in the threemonth follow-up. Ectasia developed in both eyes with a significant temporal steepening pattern (K-max: 43.1 D and K-min: 42.3 D in the right eye; and K-max: 44.2 D and K-min: 42.4 D in the left eye in the last follow-up). The postoperative CCT at five years was $521 \mu \mathrm{m}$ in the right eye and $491 \mu \mathrm{m}$ in the left eye. The right eye showed a BSCVA of $7 / 10$ with a refractive error of $-0.75-75$, while the left eye showed a BSCVA of $5 / 10$, with a refractive error of $+0.50-1.50 \times 80 \mathrm{D}$ in the last follow-up.

CASE 3: A 46-year-old male underwent Lasik surgery only in the right eye, with a preoperative refractive error of $-4.75-1.75 \times 105$; the left eye showed no refractive error. Preoperatively, the BSCVA was 10/10 in both eyes. The preoperative corneal topographic pattern was a symmetric bow-tie in the right eye (K-max: 43.2 D and K-min: 41.8 D). The preoperative CCT was $495 \mu \mathrm{m}$ in the right eye. The right eye developed corneal ectasia (K-max: $38.9 \mathrm{D}$ and K-min: $38.4 \mathrm{D}$ ) in the last follow-up. The postoperative CCT at five years was $396 \mu \mathrm{m}$. In the last follow-up, the eye with a BSCVA of $6 / 10$ showed no refractive error.

CASE 4: A 47-year-old male underwent Lasik surgery only in the left eye with a preoperative refractive error of $-3.75-1.25 \times 77$; the right eye showed no refractive error. The BSCVA was $9 / 10$ in the left eye and 10/10 in the right eye preoperatively. The preoperative corneal topographic pattern was inferior steepening (K-max: $43.3 \mathrm{D}$ and K-min: $42.9 \mathrm{D}$ ), and the preoperative CCT was $480 \mu \mathrm{m}$. The eye developed corneal ectasia (K-max: $39.9 \mathrm{D}$ and K-min: $39.5 \mathrm{D}$ ) in the last follow-up. The postoperative CCT at five years was $410 \mu \mathrm{m}$. In the last follow-up, the eye showed a BSCVA of 5/10 with a refractive error of $-0.50 \mathrm{D}$.

3.7. Femto-Lasik Surgery. Forty-four eyes of 24 patients with KCS were considered eligible for Femto-Lasik surgery.

3.8. Refraction and Vision Acuity Results. The BSCVA indicated no significant change in the three-month and five-year follow-ups, compared to the preoperative values $(P=0.18$ and $P=0.109$, respectively). Figure 1 presents the gains and losses of BSCVA lines five years after surgery. In the last follow-up, the BSCVA was lost in no cases; two cases showed a one-line gain; one case showed a two-line gain; the other cases maintained their preoperative BSCVA. The mean SE decreased significantly by $3.13 \pm 2.57 \mathrm{D}$ at three months $(P<0.001)$ and by $3.21 \pm 2.49 \mathrm{D}$ in the last follow-up $(P<0.001)$. SE did not change significantly from the three-month follow-up to the last follow-up $(P>0.05)$. However, the cylindrical component of refraction decreased significantly by $0.96 \pm 1.30 \mathrm{D}$ at three months $(P<0.001)$ and by $0.98 \pm 1.36 \mathrm{D}$ in the last follow-up $(P<0.001)$. However, astigmatism did not change significantly from the three-month follow-up to the last follow-up $(P>0.05)$. The subgroups, based on the orientation of the preoperative refractive cylinder axis, were as follows: againstthe-rule, consisting of one eye $(2.27 \%)$; with-the-rule, consisting of 33 eyes (75\%); and oblique, consisting of three eyes (6.81\%).

3.9. Topographic Results. There were significant reductions in the mean CCT and the mean thinnest point of the cornea from $544.77 \pm 25.52 \mu \mathrm{m}$ and $533.77 \pm 26.29 \mu \mathrm{m}$ preoperatively to $456.64 \pm 42.79 \mu \mathrm{m} \quad(P<0.001) \quad$ and $\quad 433.02 \pm 47.32 \mu \mathrm{m}$ $(P<0.001)$ in the last follow-up, respectively. The mean values of maximum and minimum curvatures reduced significantly from $45.45 \pm 1.53 \mathrm{D}$ and $43.58 \pm 1.16 \mathrm{D}$ preoperatively to $41.36 \pm 1.55 \mathrm{D}(P<0.001)$ and $40.12 \pm 1.51 \mathrm{D}(P<0.001)$ in the last follow-up, respectively. According to the curvature shape analysis with the Orbscan system, it was found that ten eyes (22.7\%) had a symmetric bow-tie pattern, two eyes $(4.5 \%)$ had a skewed radial axis, five eyes (11.3\%) had superior steepening, and 27 eyes $(61.3 \%)$ had inferior steepening (Figure 1). It should be noted that during this study, no case of corneal ectasia or unusual problems were identified.

\section{Discussion}

Patients with KCS show complete contraindication to refractive surgery [3]. Some studies [21, 22] have shown that refractive surgery must be avoided for patients with KCS since this disorder may develop over time, or the surgery may lead to disease progression. On the other hand, some studies $[23,24]$ have shown that refractive findings in individuals with normal corneal topographic patterns are indistinguishable from those of patients with KCS or manifest keratoconus. One of the unresolved problems of refractive surgery is corneal ectasia. Studies have described the preoperative risk factors for corneal ectasia following refractive surgery, including the low preoperative thickness of the cornea and RSB, high myopia, abnormal corneal topography, and younger age [17]. However, it should be noted that ectasia may affect individuals without an evident risk factor [25]. Therefore, in the present study, we aimed to evaluate the outcomes of keratorefractive surgeries in KCS patients. We compared the five-year follow-up results of PRK, Femto-Lasik, and Lasik surgeries in these patients.

In the present study, no significant difference was found between the preoperative and postoperative mean values of BSCVA. Our results showed that BSCVA in the Femto-Lasik group did not lead to the loss of lines after surgery. In the last follow-up, $100 \%$ of Femto-Lasik cases, $95.73 \%$ of PRK cases, and $90.62 \%$ of Lasik cases showed BSCVA of 20/20; in other words, better vision improvement was observed in the Femto-Lasik group. Some studies have reported better visual acuity in correcting high myopia with Lasik than PRK $[26,27]$. In this regard, Gu et al. [7] performed PRK for 62 
eyes of 42 patients with KCS and found that visual acuity improved significantly in the five-year follow-up. Moreover, Khakshoor et al. [28] investigated 38 eyes of 21 subjects over 40 years of age with stable keratoconus (grades I-II) and found that the uncorrected distance visual acuity (UDVA) was $20 / 20$ in 22 eyes and 20/25 in eight eyes in the last follow-up. Two other studies showed that UCVA and BCVA were stable during the follow-up of forme fruste and mild keratoconus patients after PRK [29, 30].

In the present study, the preoperative SE was greater in the Lasik group (-3.99 D) compared to the PRK (-3.67 D) and Femto-Lasik $(-3.28 \mathrm{D})$ groups. The mean preoperative SE and cylindrical power decreased significantly in the last follow-up. These results are in line with a study by Cennamo et al. [30], who investigated 25 eyes with grade II keratoconus treated by topography-guided PRK. In their study, significant stable improvements were reported in both cylindrical and spherical components of refraction during a two-year follow-up. In our study, none of the Femto-Lasik patients showed residual ametropia more than $1.0 \mathrm{D}$ in the last follow-up, and $95.4 \%$ of eyes were within $\pm 0.50 \mathrm{D}$ of refractive error. On the other hand, the prevalence of eyes within $\pm 0.50 \mathrm{D}$ of refractive error was $96.6 \%$ in the PRK group and $92.7 \%$ in the Lasik group. Also, $1.4 \%$ and $3.1 \%$ of cases showed residual ametropia of more than $1 \mathrm{D}$ in the PRK and Lasik groups, respectively.

In a study by $\mathrm{Li}$ et al. [31], 60.4\% of eyes with high myopia were within $\pm 0.5 \mathrm{D}$ of residual refractive error at three months following the Femto-Lasik surgery. Also, Katz et al. [32] compared the results of PRK and Lasik surgeries for the correction of astigmatism more than $3 \mathrm{D}$ and found similar efficacy of these methods. The upper limit of myopic refractive error for Lasik surgery was arbitrarily chosen as $12.0 \mathrm{D}$ [33]. Although corneal ectasia has been reported in eyes with lower myopia degrees (range: $-4.0 \mathrm{D}$ to $-7.0 \mathrm{D}$ ) corrected with Lasik surgery [34], in the current study, of 11 patients with corneal ectasia, there were four cases of high myopia, one case of moderate myopia, one case of low myopia, two cases of high astigmatism, three cases of moderate astigmatism, and one case of low astigmatism in the PRK group. Also, there were three cases of moderate hyperopia, two cases of moderate myopia, three cases of moderate astigmatism, and two cases of high astigmatism in the Lasik group. It seems that the myopia degree alone is a poor indicator of ectasia in our study population.

In the current study, the preoperative CCT varied from $424 \mu \mathrm{m}$ to $599 \mu \mathrm{m}$ in the PRK group, from $480 \mu \mathrm{m}$ to $618 \mu \mathrm{m}$ in the Lasik group, and from $483 \mu \mathrm{m}$ to $604 \mu \mathrm{m}$ in the FemtoLasik group. The preoperative CCT was up to $500 \mu \mathrm{m}$ in 132 eyes $(40.4 \%)$ in the PRK group, 12 eyes $(12.5 \%)$ in the Lasik group, and two eyes (4.5\%) in the Femto-Lasik group. Of 11 cases of ectasia following refractive surgery, three cases in the PRK group and two cases in the Lasik group showed CCT less than $500 \mu \mathrm{m}$.

There are several successful studies about Lasik surgery for individuals with corneas thinner than 500 or $470 \mu \mathrm{m}$ $[35,36]$. Kremer et al. [37] reported that Lasik surgery is a safe method for moderate to high myopic eyes with CCT thinner than $500 \mu \mathrm{m}$ (range: $456 \mu \mathrm{m}$ to $498 \mathrm{~mm}$ ) in the three- year follow-up. Moreover, Caster et al. performed Lasik surgery and reported no cases of keratectasia in 109 eyes with SE of -7.75 to +3.13 and CCT of $452 \mu \mathrm{m}$ to $500 \mu \mathrm{m}$ [38]. Randleman et al. also showed that ectatic corneas had a significantly thinner thickness compared to the controls; the mean CCT was one standard deviation below the mean CCT of the controls before surgery [17]. Therefore, a low preoperative CCT may be an indicator of an abnormal cornea, where keratoconus is expected to progress.

In the present study, the minimum RSB thickness in the PRK, Lasik, and Femto-Lasik groups was 308, 288, and $353 \mu \mathrm{m}$, respectively, in the last follow-up. Rao and Epstein [10] reported that the main risk factors for corneal ectasia following refractive surgery include a preexisting abnormal corneal topography and RSB thickness. Moreover, Kymionis et al. [35] determined the RSB thickness of eyes with a thin CCT, for which PRK or Lasik surgery was performed to correct myopia. The lowest RSB thickness was $308 \mu \mathrm{m}$ in the PRK group and $276 \mu \mathrm{m}$ in the Lasik group. After at least a one-year follow-up, no complications were found. Khakshoor et al. [28] also reported that RSB thickness of more than $400 \mu \mathrm{m}$ is safe for keratoconus patients with a mean age of 44 years. Overall, it is necessary to maintain a thickness of at least $250 \mu \mathrm{m}$ at the center of stroma following refractive surgery [39], while preserving at least half of the initial corneal stromal thickness is a more conservative approach [40]. In our study, all cases of ectasia following PRK and Lasik surgeries had RSB thickness of more than $300 \mu \mathrm{m}$. Generally, the main difference between PRK and Lasik surgeries is the way that the corneal flap is created, which can be the main factor leading to the destabilization of the cornea.

The femtosecond lasers are believed to create a thin flap [18]. The flap is regarded as a more critical risk factor than the excimer ablation depth, as the anterior stroma layers seem to have greater biochemical strength than the corneal layers [41]. According to the literature, the lowest and greatest keratocyte densities are related to the posterior (40\%) and anterior (10\%) aspects of the stroma, respectively $[42,43]$. In our study, the absence of corneal ectasia in the Femto-Lasik group could be related to the successful management of the shape, consistency, and less thickness variation of the flaps. Another explanation for the progression of ectasia in our subjects may be stromal hydration. A flap using a microkeratome is usually created over a wet cornea, while a femtosecond flap dehydrates the stroma [44].

After the introduction of femtosecond lasers, anecdotal evidence showed that the prevalence of ectasia has reduced. Moshirfar et al. [45] reported that the prevalence of ectasia was one in 2000 patients $(0.05 \%)$ following Femto-Lasik surgery. In a study by Klein et al. [46], the prevalence of corneal ectasia was estimated at $0.04 \%$, while other researchers estimated rates up to $0.9 \%$ for microkeratome flaps [47-50]. Based on these findings, we can conclude that RSB thickness of $250 \mu \mathrm{m}$ does not indicate a safety border, as neither RSB thickness below $250 \mu \mathrm{m}$ ensures ectasia, nor RSB thickness above $250 \mu \mathrm{m}$ indicates protection against ectasia.

All subjects in the present study were followed up for five years. Kasparova and Kasparov [51] reported that $8.6 \%$ of 
eyes showed keratoconus progression within the first six months following refractive surgery. In addition, Koller et al. [52] recommended that corneal topography should be monitored for up to five years after PRK to ensure that it does not trigger the progression of keratoconus in the eyes, which were found to be stable for a long period postoperatively. According to the analysis of the corneal curvature shape with the Orbscan system, $16.6 \%$ of ectasia cases showed an inferior steepening pattern, $16.6 \%$ had a superior steepening pattern, and $66.6 \%$ showed a symmetric bow-tie pattern preoperatively in the PRK group. Also, $40 \%$ and $60 \%$ of our ectasia cases had superior steepening and inferior steepening topographic patterns preoperatively in the Lasik group, respectively.

Unilateral ectasia developed in some patients undergoing bilateral surgery in our study. We concluded that if a patient has an abnormal topographic pattern in each eye, the surgeon must avoid refractive surgery. Ectasia may also progress in patients with a symmetric bow-tie pattern or a normal topographic pattern. In our study, $36 \%$ of ectasia cases had symmetric topographic patterns preoperatively. Therefore, a thorough assessment of the preoperative topographic map is necessary, and caution must be taken if any abnormal topographic pattern, such as asymmetric superior steepening, inferior corneal steepening, or a skewed radial axis [18], is found.

In the current study, three cases of ectasia in the PRK group and no cases of ectasia in the Lasik group had central corneal curvatures more than $47.0 \mathrm{D}$ preoperatively. In a study by Cennamo et al. [30], the maximum keratometry reading was $52.09 \pm 3.47$. In their study, improvement of clinical findings and videokeratography indices was reported in patients with grade 2 keratoconus during a two-year follow-up. Therefore, central corneal curvature findings do not seem to be particularly useful screening criteria.

In conclusion, our study showed the high risk of postoperative ectasia in eyes with KCS after keratorefractive surgeries, although the Femto-Lasik surgery provided better results than Lasik and PRK surgeries. Based on our findings, it seems that no specific factor can distinguish all at-risk patients. Alternatively, several variables must be considered to select candidates for refractive surgery. Also, the surgical criteria are suggested to be evaluated case by case, and the patients must be followed up to assess corneal topography and refraction stability. It can be concluded that Femto-Lasik surgery provides better outcomes than Lasik and PRK surgeries.

\section{Data Availability}

The data are available upon reasonable request.

\section{Conflicts of Interest}

The authors do not have any conflicts of interest.

\section{References}

[1] J. T. Holladay, "Corneal topography using the holladay diagnostic summary," Journal of Cataract \& Refractive Surgery, vol. 23, no. 2, pp. 209-221, 1997.
[2] N. S. Kalin, N. Maeda, S. D. Klyce, S. Hargrave, and S. E. Wilson, "Automated topographic screening for keratoconus in refractive surgery candidates," The CLAO Journal: Official Publication of the Contact Lens Association of Ophthalmologists, Inc, vol. 22, no. 3, pp. 164-167, 1996.

[3] J. B. Randleman, "Post-laser in-situ keratomileusis ectasia: current understanding and future directions," Current Opinion in Ophthalmology, vol. 17, no. 4, pp. 406-412, 2006.

[4] M. Mohammadpour, "Corneal ectasia after LASIK in one eye and uneventful PRK in the fellow eye," Journal of Cataract \& Refractive Surgery, vol. 33, no. 10, p. 1677, 2007.

[5] M. Mohammadpour, "Risk for ectasia with LASIK," Journal of Cataract \& Refractive Surgery, vol. 34, no. 2, pp. 181-182, 2008.

[6] E. Chelala, H. El Rami, A. Dirani, A. Fadlallah, O. Fakhoury, and E. Warrak, "Photorefractive keratectomy in patients with mild to moderate stable keratoconus: a five-year prospective follow-up study," Clinical Ophthalmology (Auckland, NZ), vol. 7, p. 1923, 2013.

[7] M. Guedj, A. Saad, E. Audureau, and D. Gatinel, "Photorefractive keratectomy in patients with suspected keratoconus: five-year follow-up," Journal of Cataract \& Refractive Surgery, vol. 39, no. 1, pp. 66-73, 2013.

[8] K. Bilgihan, S. C. Özdek, O. Konuk, F. Akata, and B. Hasanreisoglu, "Results of photorefractive keratectomy in keratoconus suspects at 4 years," Journal of Refractive Surgery, vol. 16, no. 4, pp. 438-443, 2000.

[9] R. Sun, H. V. Gimbel, and G. B. Kaye, "Photorefractive keratectomy in keratoconus suspects," Journal of Cataract \& Refractive Surgery, vol. 25, no. 11, pp. 1461-1466, 1999.

[10] S. N. Rao and R. J. Epstein, "Early onset ectasia following laser in situ keratomileusus: case report and literature review," Journal of Refractive Surgery, vol. 18, no. 2, pp. 177-184, 2002.

[11] B. J. Randleman, A. I. Caster, C. S. Banning, and D. R. Stulting, "Corneal ectasia after photorefractive keratectomy," Journal of Cataract \& Refractive Surgery, vol. 32, no. 8, pp. 1395-1398, 2006.

[12] A. V. Ljubimov and M. Saghizadeh, "Progress in corneal wound healing," Progress in Retinal and Eye Research, vol. 49, pp. 17-45, 2015.

[13] M. V. Netto, R. R. Mohan, A. E. K. Hutcheon, J. D. Zieske, and S. E. Wilson, "Wound healing in the cornea," Cornea, vol. 24, no. 5, pp. 509-522, 2005.

[14] S. Z. Scalinci, L. Scorolli, A. Meduri, P. L. Grenga, G. Corradetti, and S. Z. Scalinci, "Effect of basic fibroblast growth factor and cytochrome c peroxidase combination in transgenic mice corneal epithelial healing process after excimer laser photoablation," Clinical Ophthalmology, vol. 5, p. 215, 2011.

[15] M. Rechichi, C. Mazzotta, S. Daya, R. Mencucci, M. Lanza, and A. Meduri, "Intraoperative OCT pachymetry in patients undergoing dextran-free riboflavin UVA accelerated corneal collagen crosslinking," Current Eye Research, vol. 41, no. 10, pp. 1310-1315, 2016.

[16] L. Buzzonetti, G. Petrocelli, P. Valente et al., "Comparison of corneal aberration changes after laser in situ keratomileusis performed with mechanical microkeratome and IntraLase femtosecond laser: 1-year follow-up," Cornea, vol. 27, no. 2, pp. 174-179, 2008.

[17] J. B. Randleman, M. Woodward, M. J. Lynn, and R. D. Stulting, "Risk assessment for ectasia after corneal refractive surgery," Ophthalmology, vol. 115, no. 1, pp. 37-50, 2008.

[18] P. S. Binder, R. L. Lindstrom, R. D. Stulting et al., "Keratoconus and corneal ectasia after LASIK," Journal of Refractive Surgery, vol. 21, no. 6, pp. 749-752, 2005. 
[19] A. Guirao, "Theoretical elastic response of the cornea to refractive surgery: risk factors for keratectasia," Journal of Refractive Surgery, vol. 21, no. 2, pp. 176-185, 2005.

[20] Z. Schlegel, T. Hoang-Xuan, and D. Gatinel, "Comparison of and correlation between anterior and posterior corneal elevation maps in normal eyes and keratoconus-suspect eyes," Journal of Cataract \& Refractive Surgery, vol. 34, no. 5, pp. 789-795, 2008.

[21] G. O. Waring, "Nomenclature for keratoconus suspects," Journal of Refractive Surgery, vol. 9, no. 3, pp. 219-222, 1993.

[22] Y. S. Rabinowitz, "Keratoconus, videokeratography, and refractive surgery," Journal of Refractive Surgery, vol. 8, no. 5, pp. 403-407, 1992.

[23] C. B. Bowman, K. P. Thompson, and R. D. Stulting, "Refractive keratotomy in keratoconus suspects," Journal of Refractive Surgery, vol. 11, no. 3, pp. 202-219, 1995.

[24] J. Mortensen, K. Carlsson, and A. Öhrstrom, "Excimer laser surgery for keratoconus," Journal of Cataract \& Refractive Surgery, vol. 24, no. 7, pp. 893-898, 1998.

[25] M. R. Santhiago, D. Smadja, B. F. Gomes et al., "Association between the percent tissue altered and post-laser in situ keratomileusis ectasia in eyes with normal preoperative topography," American Journal of Ophthalmology, vol. 158, no. 1, pp. 87-95, 2014.

[26] J. L. Alio, D. Ortiz, O. Muftuoglu, and M. J. Garcia, “Ten years after photorefractive keratectomy (PRK) and laser in situ keratomileusis (LASIK) for moderate to high myopia (control-matched study)," British Journal of Ophthalmology, vol. 93, no. 10, pp. 1313-1318, 2009.

[27] M. Rosman, J. L. Alió, D. Ortiz, and J. J. Perez-Santonja, "Comparison of LASIK and photorefractive keratectomy for myopia from -10.00 to -18.00 diopters 10 Years after surgery," Journal of Refractive Surgery, vol. 26, no. 3, pp. 168-176, 2010.

[28] H. Khakshoor, F. Razavi, A. Eslampour, and A. Omdtabrizi, "Photorefractive keratectomy in mild to moderate keratoconus: outcomes in over 40-year-old patients," Indian Journal of Ophthalmology, vol. 63, no. 2, p. 157, 2015.

[29] N. Alpins and G. Stamatelatos, "Customized photoastigmatic refractive keratectomy using combined topographic and refractive data for myopia and astigmatism in eyes with forme fruste and mild keratoconus," Journal of Cataract \& Refractive Surgery, vol. 33, no. 4, pp. 591-602, 2007.

[30] G. Cennamo, A. Intravaja, G. Marotta, D. Boccuzzi, and G. Cennamo, "Treatment of keratoconus by topographyguided customized photorefractive keratectomy: two-year follow-up study," Journal of Refractive Surgery, vol. 24, no. 2, pp. 145-149, 2008.

[31] H. Li, T. Sun, M. Wang, and J. Zhao, "Safety and effectiveness of thin-flap LASIK using a femtosecond laser and microkeratome in the correction of high myopia in Chinese patients," Journal of Refractive Surgery, vol. 26, no. 2, pp. 99-106, 2010.

[32] T. Katz, L. Wagenfeld, P. Galambos, B. große Darrelmann, G. Richard, and S. J. Linke, "LASIK versus photorefractive keratectomy for high myopic (>3 diopter) astigmatism," Journal of Refractive Surgery, vol. 26, 2013.

[33] I. G. Pallikaris and D. S. Siganos, "Excimer laser in situ keratomileusis and photorefractive keratectomy for correction of high myopia," Journal of Refractive Surgery, vol. 10, no. 5, pp. 498-510, 1994.

[34] P. S. Amoils, M. B. Deist, P. Gous, and P. M. Amoils, "Iatrogenic keratectasia after laser in situ keratomileusis for less than -4.0 to -7.0 diopters of myopia," Journal of Cataract \& Refractive Surgery, vol. 26, no. 7, pp. 967-977, 2000.

[35] G. D. Kymionis, D. Bouzoukis, V. Diakonis et al., "Long-term results of thin corneas after refractive laser surgery," American Journal of Ophthalmology, vol. 144, no. 2, pp. 181-185, 2007.

[36] M. Tomita, M. Watabe, M. Mita, and G. O. Waring, "Longterm observation and evaluation of femtosecond laser-assisted thin-flap laser in situ keratomileusis in eyes with thin corneas but normal topography," Journal of Cataract \& Refractive Surgery, vol. 40, no. 2, pp. 239-250, 2014.

[37] I. Kremer, I. Bahar, A. Hirsh, and S. Levinger, "Clinical outcome of wavefront-guided laser in situ keratomileusis in eyes with moderate to high myopia with thin corneas," Journal of Cataract \& Refractive Surgery, vol. 31, no. 7, pp. 1366-1371, 2005.

[38] A. I. Caster, D. W. Friess, and R. J. Potvin, "Absence of keratectasia after LASIK in eyes with preoperative central corneal thickness of 450 to 500 microns," Journal of Refractive Surgery, vol. 23, no. 8, pp. 782-788, 2007.

[39] T. Seiler, K. Koufala, and G. Richter, "Iatrogenic keratectasia after laser in situ keratomileusis," Journal of Refractive Surgery, vol. 14, no. 3, pp. 312-317, 1998.

[40] C.-K. Joo and T.-G. Kim, "Corneal ectasia detected after laser in situ keratomileusis for correction of less than -12 diopters of myopia," Journal of Cataract \& Refractive Surgery, vol. 26, no. 2, pp. 292-295, 2000.

[41] D. Park, E. Perez, and D. Miller, "Corneal lamellar strength as determined by thickness position, and fibril orientation," Investigative Ophthalmology \& Visual Science, vol. 26, 1995.

[42] T. Møller-Pedersen, T. Ledet, and N. Ehlers, "The keratocyte density of human donor corneas," Current Eye Research, vol. 13, no. 2, pp. 163-169, 1994.

[43] S. V. Patel, J. W. McLaren, D. O. Hodge, and W. M. Bourne, "Normal human keratocyte density and corneal thickness measurement by using confocal microscopy in vivo," Investigative Ophthalmology \& Visual Science, vol. 42, no. 2, pp. 333-339, 2001.

[44] S. Patel, J. L. Alió, and A. Artola, "Changes in the refractive index of the human corneal stroma during laser in situ keratomileusis," Journal of Cataract \& Refractive Surgery, vol. 34, no. 7, pp. 1077-1082, 2008.

[45] M. Moshirfar, J. G. Smedley, V. Muthappan, A. Jarsted, and E. M. Ostler, "Rate of ectasia and incidence of irregular topography in patients with unidentified preoperative risk factors undergoing femtosecond laser-assisted LASIK," Clinical Ophthalmology (Auckland, NZ), vol. 8, p. 35, 2014.

[46] S. R. Klein, R. J. Epstein, J. B. Randleman, and R. D. Stulting, "Corneal ectasia after laser in situ keratomileusis in patients without apparent preoperative risk factors," Cornea, vol. 25, no. 4, pp. 388-403, 2006.

[47] P. S. Binder, "Analysis of ectasia after laser in situ keratomileusis: risk factors," Journal of Cataract \& Refractive Surgery, vol. 33, no. 9, pp. 1530-1538, 2007.

[48] M. C. Chen, N. Lee, N. Bourla, and R. D. Hamilton, "Corneal biomechanical measurements before and after laser in situ keratomileusis," Journal of Cataract \& Refractive Surgery, vol. 34, no. 11, pp. 1886-1891, 2008.

[49] M. D. Twa, J. J. Nichols, C. E. Joslin et al., "Characteristics of corneal ectasia after LASIK for myopia," Cornea, vol. 23, no. 5, pp. 447-457, 2004.

[50] P. I. Condon, M. O’Keefe, and P. S. Binder, "Long-term results of laser in situ keratomileusis for high myopia: risk for ectasia," Journal of Cataract \& Refractive Surgery, vol. 33, no. 4, pp. 583-590, 2007. 
[51] E. A. Kasparova and A. A. Kasparov, "Six-year experience with excimer laser surgery for primary keratoconus in Russia," Journal of Refractive Surgery, vol. 19, no. 2, pp. S250-S254, 2003.

[52] T. Koller, H. P. Iseli, C. Donitzky, D. Ing, N. Papadopoulos, and T. Seiler, "Topography-guided surface ablation for forme fruste keratoconus," Ophthalmology, vol. 113, no. 12, pp. 2198-2202, 2006. 